\title{
Discharge identity of medullary inspiratory neurons is altered during repetitive fictive cough
}

\author{
L. S. Segers' ${ }^{1}$, S. C. Nuding ${ }^{1}$, A. Vovk ${ }^{2}$, T. Pitts' ${ }^{2}$, D. M. Baekey ${ }^{2}$, R. O'Connor ${ }^{1}$, K. F. Morris ${ }^{1}$, B. G. Lindsey ${ }^{1}$, \\ R. Shannon ${ }^{1}$ and Donald C. Bolser ${ }^{2}$.
}

${ }^{1}$ Department of Molecular Pharmacology and Physiology, Morsani College of Medicine, University of South Florida, Tampa, FL, USA

2 Department of Physiological Sciences, College of Veterinary Medicine, University of Florida, Gainesville, FL, USA

\section{Edited by:}

Raimond L. Winslow, The Johns

Hopkins University, USA

Reviewed by:

Daniel Goldman, The University of

Western Ontario, Canada

Ravi Radhakrishnan, University of

Pennsylvania, USA

*Correspondence:

Donald C. Bolser, Department of Physiological Sciences, University of Florida, P.O. Box 100144, Gainesville, FL 32610-0144, USA.

e-mail:bolser@ufl.edu
This study investigated the stability of the discharge identity of inspiratory decrementing (I-Dec) and augmenting (I-Aug) neurons in the caudal (cVRC) and rostral (rVRC) ventral respiratory column during repetitive fictive cough in the cat. Inspiratory neurons in the cVRC $(n=23)$ and rVRC $(n=17)$ were recorded with microelectrodes. Fictive cough was elicited by mechanical stimulation of the intrathoracic trachea. Approximately $43 \%$ (10 of 23) of I-Dec neurons shifted to an augmenting discharge pattern during the first cough cycle (C1). By the second cough cycle (C2), half of these returned to a decrementing pattern. Approximately 94\% (16 of 17) of I-Aug neurons retained an augmenting pattern during $\mathrm{C} 1$ of a multi-cough response episode. Phrenic burst amplitude and inspiratory duration increased during $\mathrm{C} 1$, but decreased with each subsequent cough in a series of repetitive coughs. As a step in evaluating the model-driven hypothesis that VRC I-Dec neurons contribute to the augmentation of inspiratory drive during cough via inhibition of VRC tonic expiratory neurons that inhibit premotor inspiratory neurons, cross-correlation analysis was used to assess relationships of tonic expiratory cells with simultaneously recorded inspiratory neurons. Our results suggest that reconfiguration of inspiratory-related sub-networks of the respiratory pattern generator occurs on a cycle-by-cycle basis during repetitive coughing.

Keywords: respiratory pattern generator, cough, breathing, inspiratory, expiratory, medulla

\section{INTRODUCTION}

Airway stimulation can elicit repetitive coughs which may outlast the duration of the stimulus in animal models (Bongianni et al., 1998; Shannon et al., 1998, 2000; Bolser and Davenport, 2000). In humans, bouts of repetitive coughing, called paroxysms, can induce significant morbidity due to ballistic motor activation of respiratory muscles and large intrathoracic and abdominal pressure changes (Morice et al., 2004). The specific physiological mechanisms that are responsible for the production of paroxysmal coughing are unknown. The lack of this knowledge is an impediment to the development of more effective cough suppressant therapies. Significant advancements have been made in understanding specific central mechanisms in the neurogenesis of single coughs from animal models (Shannon et al., 1998, 2000; Baekey et al., 2001, 2003). Preliminary evidence from this laboratory has suggested the presence of unique behavior of previously identified central elements during repetitive coughing. Elucidation of these mechanisms, and their role in governing the pattern of coughing, may lead to new avenues for the pharmacological suppression of cough.

In recent models for cough motor pattern generation, brainstem neurons that generate and shape breathing patterns are reconfigured to produce a cough; their responses and interactions during cough have been previously described (Shannon et al., 1996, 1998; Baekey et al., 2001, 2003; Bolser et al., 2003, 2006). Briefly, respiratory neurons that exhibit an augmenting or decrementing discharge pattern during the inspiratory phase of eupnea (I-Aug and I-Dec, respectively) are excited by peripheral sensory airway afferents via second order neurons in the nucleus tractus solitarius, resulting in inhibition of expiratory neuronal activity and an increase in the ramp, duration, and amplitude of phrenic activity. A decrease in inspiratory (I-Aug and I-Dec) and an increase in expiratory augmenting and decrementing (E-Aug and E-Dec, respectively) neural activity terminate the inspiratory phase and initiate the compressive and expulsive phases of cough.

Most inspiratory neurons in defined regions within the medulla are proposed to have specific roles in cough motor pattern generation. Premotor I-Aug neurons in the caudal ventrolateral respiratory column (cVRC) excite inspiratory motoneurons, such as those in the phrenic motor nucleus, that innervate inspiratory pump muscles, including the diaphragm. Propriobulbar I-Dec neurons shape the discharge pattern of I-Aug neurons (via inhibition), inhibit E-Aug and E-Dec neurons and help regulate inspiratory duration along with I-Driver neurons (for review refer to Shannon et al., 1996). Previous studies have shown that a group of I-Dec neurons in the cVRC and E-Aug neurons in the rostral ventrolateral respiratory column (rVRC) change their pattern of discharge, or discharge identity, during single fictive coughs: $82 \%$ of the caudal I-Dec neurons switched to an augmenting discharge identity (Shannon et al., 1998) and 50\% of the rostral E-Aug neurons switched to a decrementing discharge identity (Oku et al., 1994; Shannon et al., 1998, 2000). In the current model, alterations of discharge identity of the rostral E-Aug population during fictive cough have been represented by separating the E-Aug neurons 
into two functional subpopulations: E-Aug early (decrementing during cough) and E-Aug late (augmenting or continuous during cough). This process highlighted heterogeneity within this population of neurons and allowed specific modeling of the unique synaptic effects that each subpopulation had on the rest of the respiratory network. For inspiratory neurons during single fictive coughs, Shannon et al. (1998) reported little change in discharge identity for both rostral and caudal I-Aug neurons, but heterogeneity among rostral I-Dec neurons, approximately half of which converted to an augmenting discharge pattern during single fictive coughs.

The results described above were from measurements of singlecough episodes and the first coughs of repetitive series. During repetitive cough episodes, phrenic amplitude can decrease with each subsequent cough (Bongianni et al., 1998), suggesting a decrease in inspiratory motor drive. Given that I-Dec neurons help shape phrenic nerve activity and hence inspiratory motor drive, it is unknown whether the shift in I-Dec discharge pattern observed during single fictive coughs is preserved during repetitive coughing. The purpose of this study was to examine the discharge pattern of I-Dec neurons in the cVRC and rVRC during eupnea, single and repetitive coughs, and recovery breaths. We speculated that the discharge identity of the I-Dec population would be labile during repetitive coughing. Furthermore, we investigated whether the stable discharge identity of I-Aug neurons during single coughs would be preserved throughout repetitive cough episodes.

Simulations of a new computational neuromechanical model (see companion manuscript in this issue - O'Connor et al., 2012) suggest that inhibitory VRC I-Dec neurons contribute to the augmentation of cough inspiratory drive, which can - via operating volume-dependent cough mechanics - increase tracheal air flow during the subsequent expulsive phase (Smith et al., 2012). The proposed circuit mechanism includes I-Dec neuron inhibition of the inspiratory phase activity of VRC tonic E-Dec neurons that, in turn, inhibit premotor inspiratory neurons. As a step in evaluating this model-driven hypothesis, we also assessed responses and short-time scale correlations of tonic expiratory neuron spike trains that were recorded simultaneously with the inspiratory neurons.

\section{MATERIALS AND METHODS SURGICAL PROCEDURE AND INSTRUMENTATION}

All experimental protocols were approved by the Institutional Animal Care and Use Committee at the University of South Florida and were conducted in accordance with the American Physiological Society's Guiding Principles in the Care and Use of Vertebrate Animals in Research and Training. Other results from some of these experiments were included in a previous report of singlecough responses to tracheal stimulation (Shannon et al., 1998). Ten cats $(2.4-5.7 \mathrm{~kg}$ ) were initially anesthetized with $22 \mathrm{mg} / \mathrm{kg}$ (iv) thiopental sodium. To reduce mucous secretion from the airways during the cough trials, $0.5 \mathrm{mg} / \mathrm{kg}$ (im) of atropine was administered. To help prevent hypotension and minimize brain stem swelling during the craniotomy, $2.0 \mathrm{mg} / \mathrm{kg}$ (iv) of dexamethasone was given. The femoral artery and vein were catheterized to monitor blood pressure, acquire blood samples and administer fluids.
Animals were placed in a stereotaxic frame and decerebrated at the midcollicular level. Anesthesia with thiopental sodium was maintained throughout the decerebration process and discontinued when this surgery was complete. After decerebration, animals were paralyzed by continuous intravenous infusion of gallamine triethiodide ( $4 \mathrm{mg} / \mathrm{kg} / \mathrm{h}$ ) and artificially ventilated through a tracheal cannula with a phrenic-driven ventilator. A bilateral thoracotomy was performed to minimize brainstem movement.

Throughout the surgery and cough protocol, end-tidal $\mathrm{CO}_{2}$ was maintained at $4-5 \%$ and the fraction of inspired $\mathrm{O}_{2}$ was increased when necessary to prevent hypoxemia. Arterial blood samples were periodically analyzed for arterial $\mathrm{PCO}_{2}, \mathrm{PO}_{2}, \mathrm{pH}$, and $\mathrm{HCO}_{3}{ }^{-}$and maintained within normal parameters. Blood pressure was maintained $\geq 100 \mathrm{mmHg}$ by intravenously administering solutions of $5 \%$ dextrose in $0.45 \% \mathrm{NaCl}, 5 \%$ dextran, or lactated Ringer's solution when needed. Body temperature was maintained at $38 \pm 0.5^{\circ} \mathrm{C}$ using a rectal temperature probe and a servo-controlled heating pad.

\section{PERIPHERAL NERVE PREPARATION AND RECORDING}

The right cranial iliohypogastric (or lumbar; $\mathrm{L}_{1}$ ) and left phrenic $\left(\mathrm{C}_{5}\right)$ nerves were desheathed and cut. Efferent activity was recorded with bipolar silver electrodes that were immersed in pools of mineral oil. The right recurrent laryngeal nerve close to the larynx was desheathed and cut. Efferent activity was recorded with bipolar silver electrodes covered with cotton saturated with mineral oil. Nerve signals were amplified and bandpass filtered $(10 \mathrm{~Hz}-10 \mathrm{kHz})$. Nerve activity at rest and during the cough protocol were recorded and monitored on a polygraph.

\section{BRAINSTEM NEURON PREPARATION AND CHARACTERIZATION}

Microelectrode neural recording and analysis has been previously described (Shannon et al., 1998, 2000; Baekey et al., 2001, 2004). Following occipital craniotomy, portions of the caudal cerebellum were suctioned to expose the medulla. The surface of the medulla was covered with warm mineral oil. Inspiratory neurons in the rostral and caudal VRC were monitored simultaneously with two independently controlled planar arrays of tungsten microelectrodes (10-12 M $\Omega$ ). Each array consisted of six to eight microelectrodes $150-200 \mu \mathrm{m}$ apart to allow for recording from separate single neurons. The depth of each electrode was adjusted using micromotor controllers. Signals were amplified and bandpass filtered $(0.1-5 \mathrm{kHz})$.

Positive collision tests were used to identify bulbospinal neurons. Briefly, $0.1 \mathrm{~ms}$ single pulses $(1-10 \mathrm{~V})$ were delivered through bipolar stainless steel electrodes in the ventral spinal cord at the T1 level contralateral to the medullary recording sites. Spiketriggered averaging of contralateral phrenic and ipsilateral recurrent laryngeal nerve efferent activities was also used to aid in the identification of phrenic premotoneurons and laryngeal pre- and motoneurons (for details of feature interpretations, see Figure 3, Shannon et al., 1998).

\section{DATA ACOUISITION AND PREPROCESSING}

Neuron signals from the microelectrodes, nerve data from the bipolar electrodes, and arterial blood and tracheal pressures were monitored during the experiment using oscilloscopes, audio 
monitors, and a polygraph and recorded on magnetic tape for subsequent offline analysis. Activities of phrenic, lumbar, and recurrent laryngeal nerves were integrated (full-wave-rectified signal to a resistor-capacitor integrator, $\tau=0.2 \mathrm{~s}$ ) to obtain moving time averages. Analog signals of the moving time averages, arterial blood and tracheal pressures, cough stimulus timing marks, and signals from each microelectrode were digitized via a 16channel analog-to-digital converter and stored on a computer for preprocessing and analysis.

Action potentials from individual respiratory neurons were converted to times of occurrence using spike-sorting software (Datawave Technology). These spike times and the analog signals described above were viewed and analyzed using the program Scope and other methods (Shannon et al., 2000).

\section{FICTIVE COUGH PROTOCOL}

Fictive cough was elicited by mechanically stimulating the midcervical to carinal regions of the intrathoracic trachea with a device constructed of two $1 \mathrm{~cm}$ loops of polyethylene tubing attached to a thin wire inserted through a port in the tracheal cannula. In eight animals, this device was deployed manually. In the remaining two animals, the device was advanced into the trachea using a custom-built controller and rotated with a frequency of $1.0 \mathrm{~Hz}$; in these cases, stimulus durations ranged from 1.5 to $4 \mathrm{~s}$. Cough was defined as an increase in the maximum amplitude of integrated phrenic nerve activity $(\geq 2 \mathrm{SD}$ above the mean maximum phrenic amplitude for the five eupneic breaths preceding the cough stimulus) that was coincident with or immediately followed by an increase in integrated lumbar nerve activity $(\geq 2$ SD above the mean of the maximum eupneic lumbar amplitude). Between trials, the polyethylene tubing was retracted into the tracheal cannula to prevent further stimulation of the trachea. The protocol consisted of at least five cough stimuli separated by $\geq 40$ s to allow for eupneic breathing to return to baseline levels. Cough response episodes consisting of two or more consecutive cough cycles were considered for analysis; single coughs were also included if the recording contained at least one instance of a multiple-cough response.

\section{DATA ANALYSIS}

Cough responses were grouped according to the number of consecutive cough cycles produced in reaction to the intra-tracheal stimulus. Individual cough cycles within a response were numbered; for example, a triple-cough response consisted of three cough cycles labeled C1, C2, and C3.

A neuron's discharge ratio during one cycle was calculated by dividing the number of spikes occurring in the first half of inspiration by the spike count in the second half; one was added to the total number of spikes in each half of the phase to avoid the presence of zero in the numerator or denominator. In some recordings, a cough response type was elicited more than once (e.g., recording four in animal D contained two instances of a double-cough response; Table 1 ). To insure that the neurons in these recordings were not over-represented within the data set, average neuronal discharge ratios were calculated for each cough cycle of the response by dividing the sum of the spikes (plus one) in the first halves by the sum of the spikes (plus one) in the second halves of the inspiratory phases of, for example, the $\mathrm{C} 1$ cycles of all the double-cough responses in that recording. In addition, average discharge ratios for all $\mathrm{C} 1$ and $\mathrm{C} 2$ cycles of multiple-cough responses were calculated for each cell. Average discharge ratios were obtained for each cell during a control period of at least $5 \mathrm{~min}$ before any stimulus protocols were presented and during the five eupneic breaths preceding and the five recovery breaths following the cough cycles.

All discharge ratios were normalized by calculating the log of the ratio. Neurons with $\log$ ratios $>0$ or $\leq 0$ were defined as having decrementing or augmenting discharge identities, respectively, during the time period for which the ratio was calculated. A neuron's control discharge identity was characterized by its average ratio during the control period.

Inspiratory neurons in the rostral and caudal areas of the ventral respiratory column were grouped based on stereotaxic coordinates; Fisher exact tests were used to investigate regional differences in discharge identity changes in response to cough stimuli.

Paired $t$-tests were used to identify differences among neuronal log discharge ratios, phrenic amplitudes, and inspiratory durations during eupneic, cough, and recovery breaths. Twosample $t$-tests assuming unequal variances were used to assess differences among specific cough cycles in single-, double-, and triple-cough episodes. Results were corrected for multiple testing by controlling the false discovery rate to 0.05 (Benjamini and Hochberg, 1995); $p \leq 0.02$ indicate significant differences.

Cross-correlation histograms (CCHs) were calculated for pairs of simultaneously recorded neurons using the entire recording; peak or trough features were identified as departures $\geq 3$ SD from the either the mean of the shift-predictor control correlogram calculated using 20 respiratory cycles at a time with all possible shifts of these cycles or the mean of a range of $\mathrm{CCH}$ bins that did not include the feature.

\section{RESULTS}

\section{DETERMINATION OF DISCHARGE IDENTITY}

The top portion of Figure 1A shows sorted neuron spike times coincident with and adjacent to the first cough $(\mathrm{C} 1)$ in a cough response episode and the eupneic breath immediately preceding it (E5) for an I-Dec (more spikes in the first half of the inspiratory phase) and an I-Aug neuron (more spikes in the second half). The inspiratory phases of the $\mathrm{E} 5$ and $\mathrm{C} 1$ cycles are indicated by a vertical gray bar; the difference in shade delineates the first half of inspiration from the second. Integrated phrenic and lumbar nerve activities are also shown in this inset; note the increases in amplitude of nerve activities and duration of inspiration during $\mathrm{C} 1$. The bottom panel of Figure 1A expands the time frame of the inset, depicting firing rate histograms of spike events (such plots of firing rate vs. time allow better visualization of neuronal discharge identity) for the same two neurons during a triple-cough response episode; the five breaths preceding (eupneic period) and following (recovery period) the cough response are also shown. The discharge patterns of these cells did not change during the cough episode. Figure $\mathbf{1 B}$ shows firing rate 
Table 1 | Detailed recording and response information.

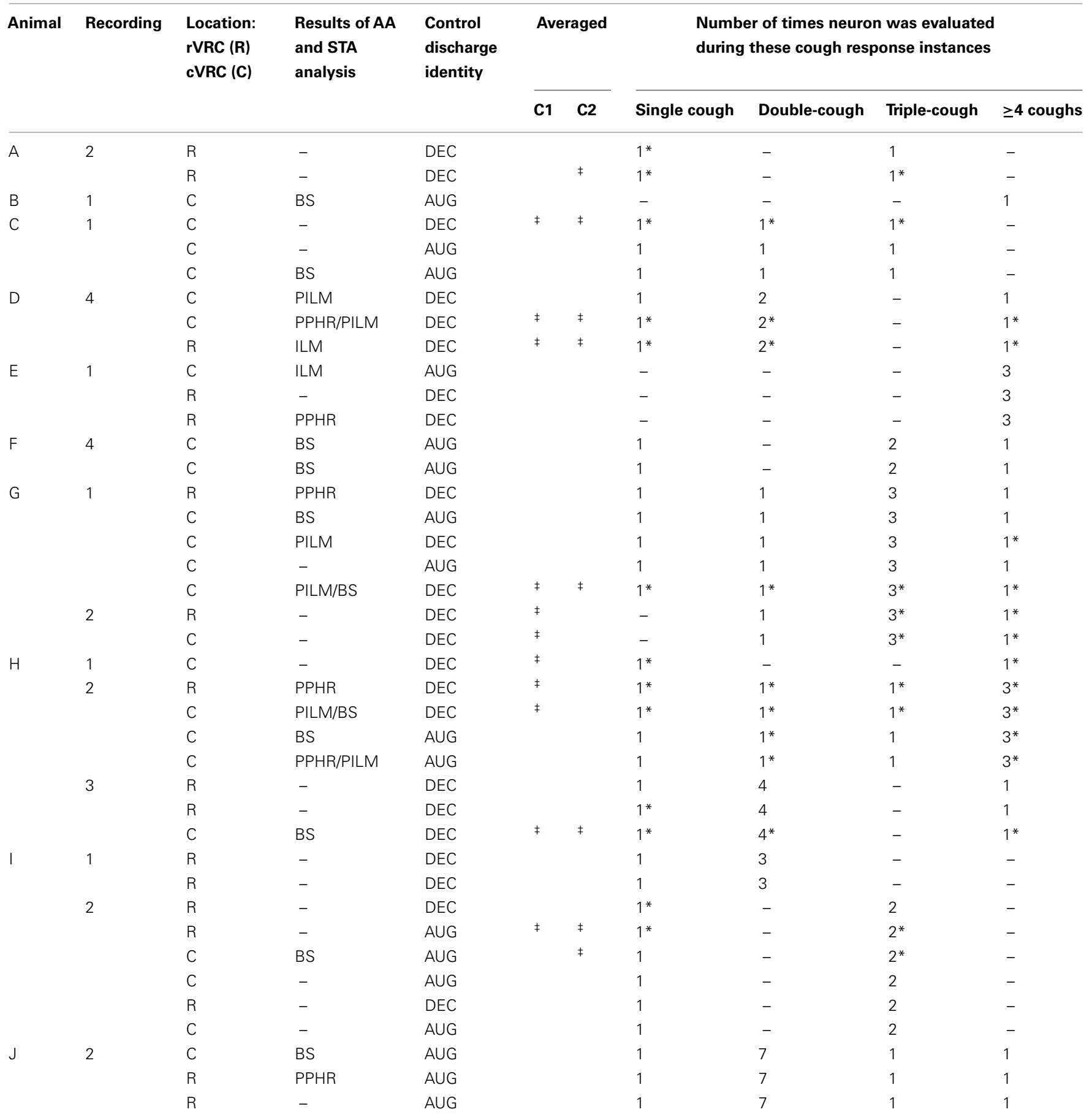

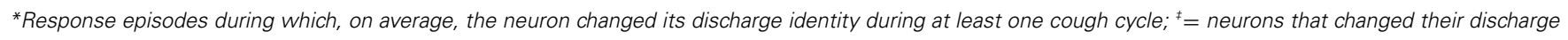

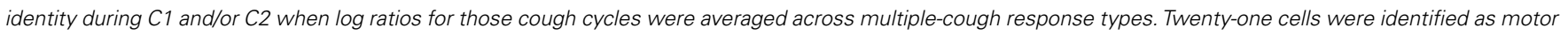
or premotor neurons based upon the results of STA of nerve activity and AA from the spinal cord. Test results for four caudal VRC cells suggested multiple projections.

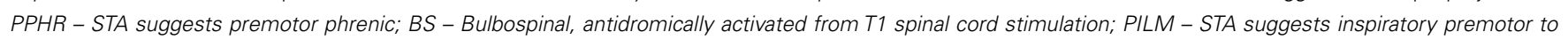
recurrent laryngeal nerve; ILM - unrectified STA suggests inspiratory recurrent laryngeal nerve motoneuron.

histograms for two I-Dec cells whose discharge identities changed from decrementing to augmenting during $\mathrm{C} 1$ (i.e., their log discharge ratios changed from $\leq 0$ to $>0$ ). By the second cough cycle,
I-Dec ${ }^{\mathrm{a}}$ returned to a decrementing pattern, whereas I-Dec ${ }^{\mathrm{b}}$ maintained an augmenting discharge throughout the repetitive cough episode. 
A

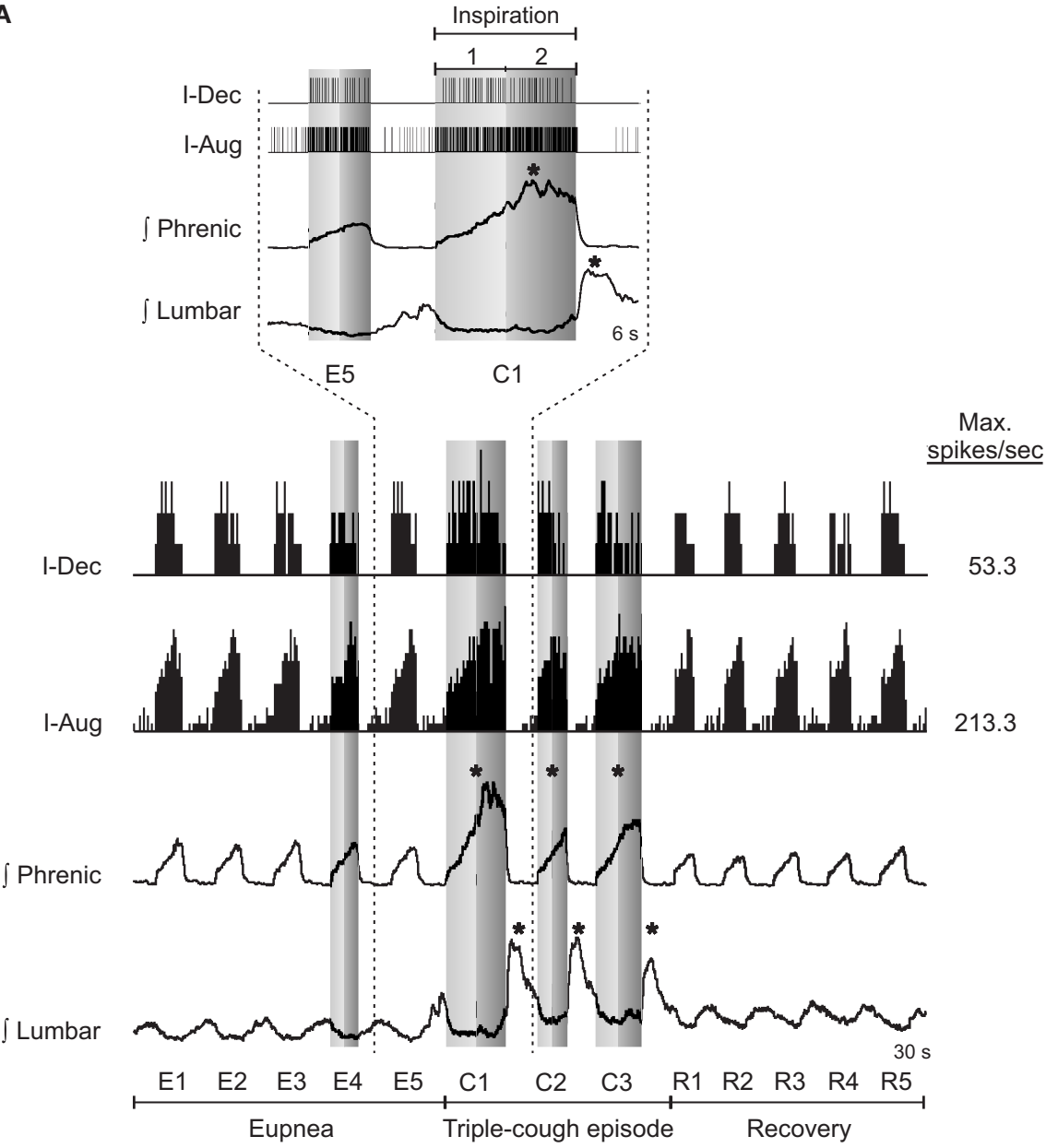

B

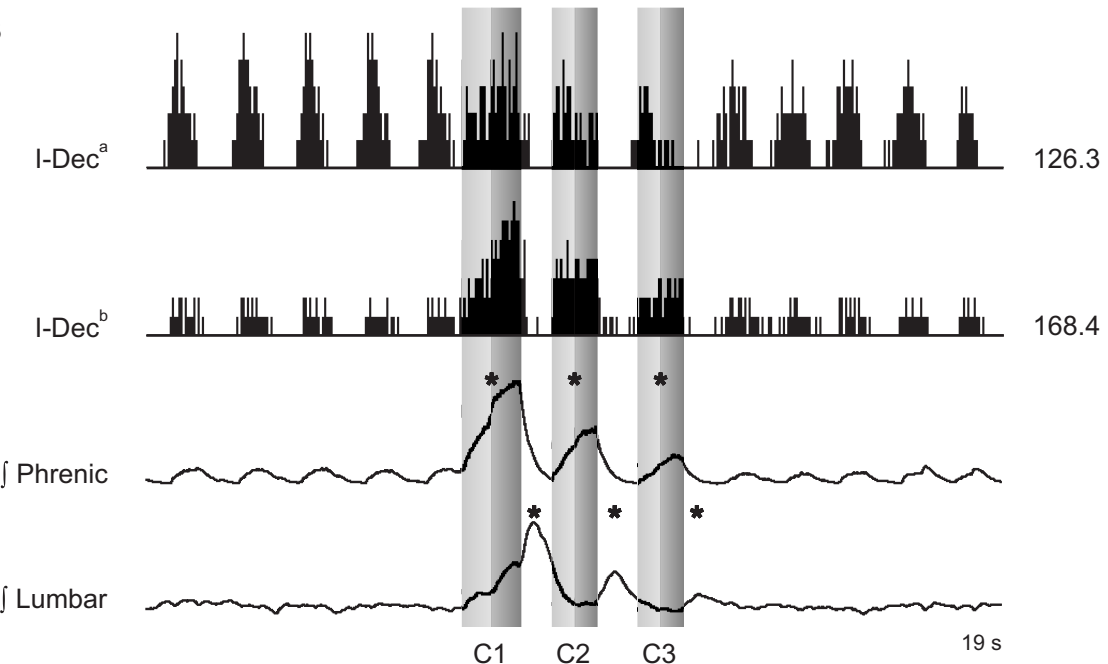

FIGURE 1 | (A) Neuronal spike times (top) and firing rate histograms (firing rate vs. time; binwidth $=75.0 \mathrm{~ms}$; bottom) of two VRC cells recorded during a triple-cough response episode; the discharge identities of these cells did not change during this cough episode. (B) Firing rate histograms (binwidth $=47.5 \mathrm{~ms}$ ) of two I-Dec neurons illustrating their change to an augmenting discharge pattern during $\mathrm{C} 1$ of the cough response; cell I-Dec ${ }^{a}$ returned to a decrementing pattern by cycle $\mathrm{C} 2$, but cell I-Dec ${ }^{\mathrm{b}}$ maintained an augmenting pattern throughout the cough episode before returning to a decrementing discharge during the recovery period. Gray vertical bars indicate inspiratory phases; the difference in shade delineates the first half of inspiration from the second. E, eupneic respiratory cycles; C, cough cycles; R, recovery cycles; ${ }^{*}$, amplitude of integrated phrenic (lumbar) nerve activity is $\geq 2 \mathrm{SD}$ above the mean maximum amplitude during eupneic period. 


\section{RECORDING LOCATIONS AND AXONAL PROJECTIONS OF NEURONS}

The stereotaxic coordinates of the recording locations of cells within the rostral VRC $(n=17)$ ranged from 2.4 to $5.0 \mathrm{~mm}$ rostral to the obex, $2.7-3.6 \mathrm{~mm}$ lateral to the midline, and $3.4-5.2 \mathrm{~mm}$ below the dorsal surface of the medulla. Caudal VRC neurons ( $n=23$ ) were located $2.0 \mathrm{~mm}$ caudal to $0.9 \mathrm{~mm}$ rostral to the obex, 3.3-3.9 mm lateral to the midline, and $2.5-4.2 \mathrm{~mm}$ below the dorsal surface.

Ten I-Dec neurons were identified as motoneurons or premotor neurons based on STA and/or antidromic activation (AA) from the T1 level of the ventral spinal cord (Table 1). The discharge identities of four of the six I-Dec cells identified as inspiratory recurrent laryngeal pre- or motoneurons changed with cough (i.e., became I-Aug) when all C1 and C2 cycles of multiple-cough episodes were averaged (see ${ }^{\ddagger}$ marking the third cell in animal D, recording 1 in Table 1); only one of the six was within the rVRC. The average discharge patterns of two of the four I-Dec neurons identified as phrenic premotor neurons became augmenting during $\mathrm{C} 1$. The three I-Dec bulbospinal neurons, all in the caudal region, changed identity with cough. Eleven I-Aug neurons were identified as motoneurons or premotor neurons. Only one of the eight I-Aug neurons found to be bulbospinal by AA, all of which were within the caudal VRC, changed to a decrementing pattern during cough. None of the I-Aug phrenic premotor $(n=2)$ or inspiratory laryngeal pre- or motoneurons $(n=2)$ exhibited a change in discharge identity. For 19 neurons, the results of AA testing and STA yielded no evidence of axonal projections to the regions tested; most of them (13 of 19) did not exhibit changed identities.

\section{DISCHARGE PATTERNS DURING SINGLE AND REPETITIVE COUGH EPISODES}

Table 1 contains detailed information about the 14 recordings and 40 neurons in the data set. Eleven single-cough and 48 multiplecough response episodes were analyzed; two or more neurons were recorded during the cough responses in all but two episodes. Note that the instances of cough response types varied from recording to recording; most neurons were evaluated for more than one type of cough response. The majority of the response episodes contained three or fewer coughs; these are examined in greater detail in later figures and paragraphs. Fourteen response episodes were comprised of four or more cough cycles (nine 4-cough and one each of 5-, 7-, 8-, 10-, and 11-cough episodes).

When log discharge ratios were considered separately for each type of multiple-cough response episode, 16 of the 40 inspiratory neurons (40\%) changed identity during at least one cycle. A greater proportion of I-Dec cells temporarily adopted an augmenting discharge pattern (12 of $23 ; 52 \%$ ) than the reverse condition: $24 \%$ of I-Aug neurons ( 4 of 17) switched to a decrementing pattern during a cough cycle (Table $\mathbf{1})$.

The average log discharge ratios for I-Dec and I-Aug neurons during eupnea (E), cough (C), and recovery breaths (R) were plotted for cough episodes consisting of one-, two-, and three-cough cycles (Figures 2,3). Figure 2 illustrates the log ratios for 21 IDec neurons recorded during a single-, double-, or triple-cough episode (left column); these data are further divided into the 14 cells that changed their discharge identity during any cycle of that cough response type (67\%; middle column) and the seven that maintained their decrementing discharge pattern throughout the cough response (33\%; right column). The average log ratio for all I-Dec neurons during C1 for single-, double-, and triple-cough episodes was significantly less than the ratios for the corresponding eupneic (each $p<0.001)$ and recovery periods $(p<0.001$, $p=0.002$, and $p=0.005$ ), indicating that, on average, the difference between neuronal spike counts in the first and second halves of inspiration was reduced during $\mathrm{C} 1$, resulting in a discharge pattern that was less decrementing. There was no difference in the log ratios calculated for all I-Dec cells during C1 among one-, two-, and three cough episodes. The log ratio during C2 for all I-Dec cells was significantly greater than the $\mathrm{C} 1 \log$ ratio $(p=0.001$ and $p=0.009$ ), but was not different than the eupneic log ratio during double- and triple-cough episodes indicating that, on the whole, I-Dec cells returned to their eupneic discharge patterns by the second cough of the series. The log ratio during C3 was not different than that during eupnea, but it was greater than the $\mathrm{C} 1 \log$ ratio $(p=0.003)$.

Figure 3 illustrates the log ratios for 15 I-Aug neurons recorded during a response episode of fewer than four coughs. As a whole, the discharge patterns of the I-Aug neurons remained augmenting in each cycle of the cough response types shown; there was no significant difference between the log discharge ratios for any cough cycle and its corresponding eupneic period. Similar to the results for I-Dec cells, there was no difference in the log ratios calculated for all I-Aug cells during C1 among one-, two-, and three cough episodes. However, the log ratio for $\mathrm{C} 1$ was lower than that of $\mathrm{C} 2$ or $\mathrm{C} 3$ during triple-cough episodes $(p=0.002$ and $p=0.003$ ). In contrast to the findings for I-Dec neurons, only four of these 15 I-Aug cells exhibited a changed discharge identity during a cough response. One neuron changed its discharge identity during $\mathrm{C} 1$ of a single-cough episode; it also changed during all cough cycles of a triple-cough response. Another neuron from the same recording had a decrementing pattern only during $\mathrm{C} 2$ of a triple-cough episode. Two cells from a different recording changed their discharge identities during $\mathrm{C} 2$ of a double-cough episode.

\section{C1 VS. C2 COMPARISON}

The average log discharge ratios during $\mathrm{C} 1$ and $\mathrm{C} 2$ of multiplecough responses for I-Dec neurons in the cVRC and rVRC were compared to investigate regional differences in response to cough stimuli (Figure 4). I-Aug neurons were not included in this analysis because our population only included three rostral neurons of this type. The average log ratio during $\mathrm{Cl}$ of the nine I-Dec cells in the cVRC was negative, indicating a change to an augmenting discharge pattern, and was significantly different from the ratios during eupnea $(p<0.001)$ and C2 $(p=0.004)$. The overall discharge pattern of caudal I-Dec neurons during C2 was decrementing and significantly different from eupnea $(p<0.001)$. I-Dec neurons in the rVRC $(n=14)$ maintained a decrementing discharge pattern during $\mathrm{C} 1$ and $\mathrm{C} 2$; however, the average log ratio for these cells was less during $\mathrm{C} 1$ compared to that during eupnea $(p=0.002)$ and $C 2(p=0.005)$. The average log ratios for $\mathrm{C} 1$ and $\mathrm{C} 2$ were significantly less in the cVRC compared to the rVRC ( $p=0.004$ and $p=0.007$, respectively), suggesting that the I-Dec neurons that shifted to an augmenting discharge pattern 


\section{I-DEC neurons}

All

A Single-cough response

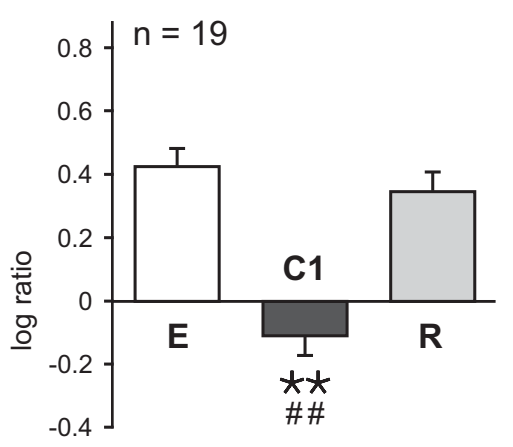

B

Double-cough response

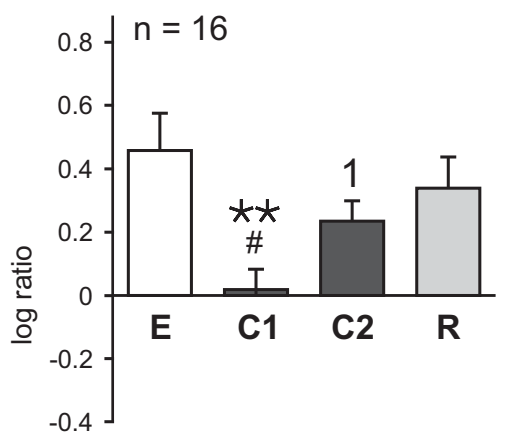

c Triple-cough response

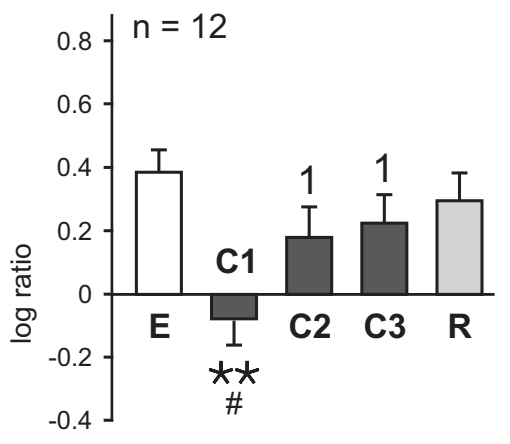

Discharge identity changed

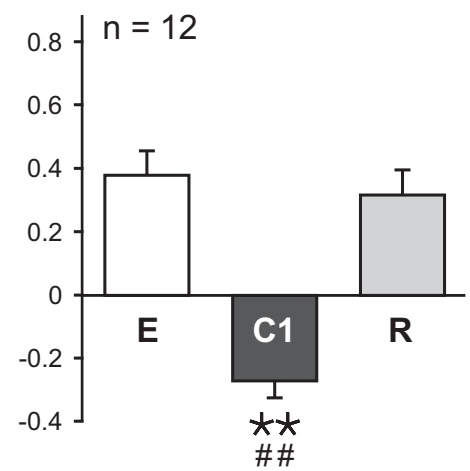

Discharge identity
unchanged

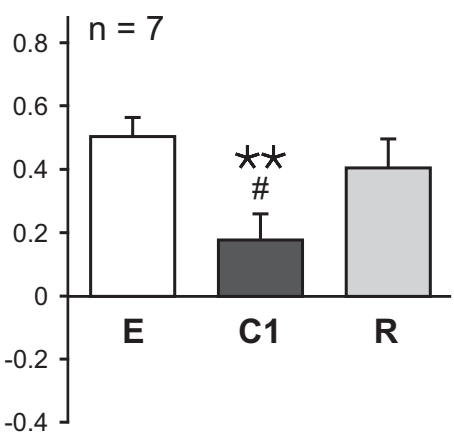

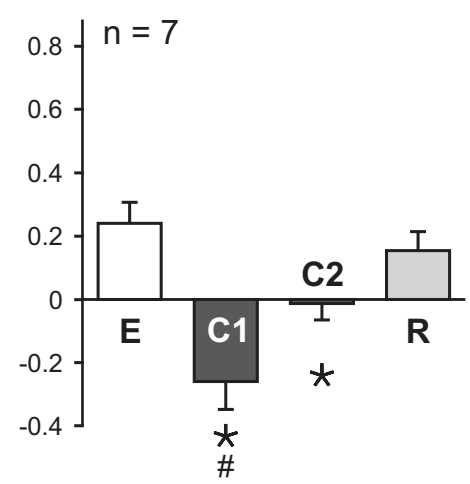
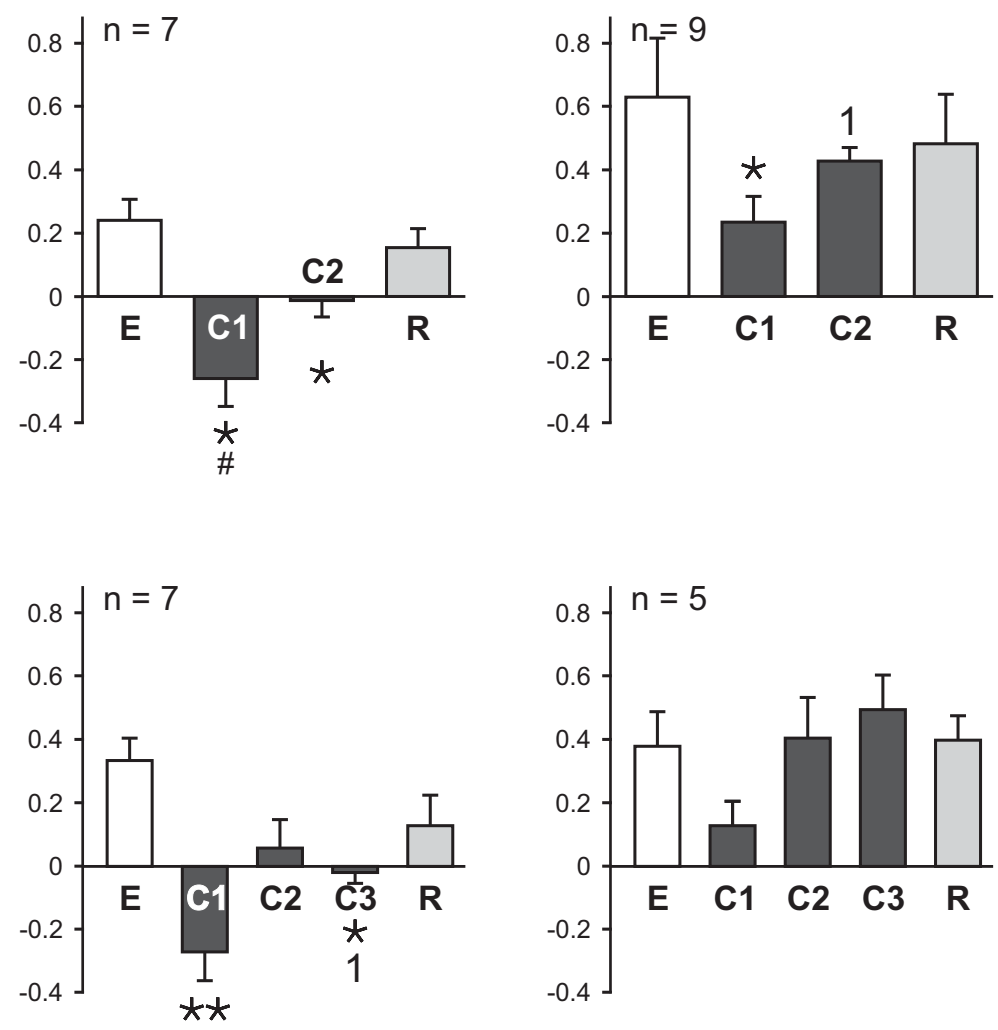

FIGURE 2 | Average log ratios of I-Dec neurons during (A) single-, (B) double-, and (C) triple-cough episodes. E represents the log ratio of the total spike counts in the five eupneic breaths immediately prior to cough onset; similarly, $\mathrm{R}$ depicts the log ratio of the counts in the five recovery breaths immediately following the cough episode. ${ }^{*}$, Significantly different from $E_{;} \#$, significantly different from $R ; 1$, significantly different from $\mathrm{C} 1$. $P$-values are indicated by one $(p<0.02)$ or two $(p<0.001)$ symbols. Number of neurons $(n)$ analyzed for each cough episode type is indicated on the plots. Some neurons were evaluated for more than one type of cough response. Error bars indicate the standard error of the mean. were mostly located within the cVRC and, indeed, a significantly greater percentage of caudal I-Dec neurons changed their discharge pattern during $\mathrm{C} 1$ (7 of $9 ; 78 \%)$ than did I-Dec cells within the rVRC (three of $14 ; 21 \%)(p<0.014$; Table 2).

\section{INSPIRATORY DRIVE} PHRENIC NERVE ACTIVITY

On average, the maximum integrated phrenic nerve amplitude increased during the first cycle of a cough episode and 


\section{All I-AUG neurons}

\section{A Single-cough response}

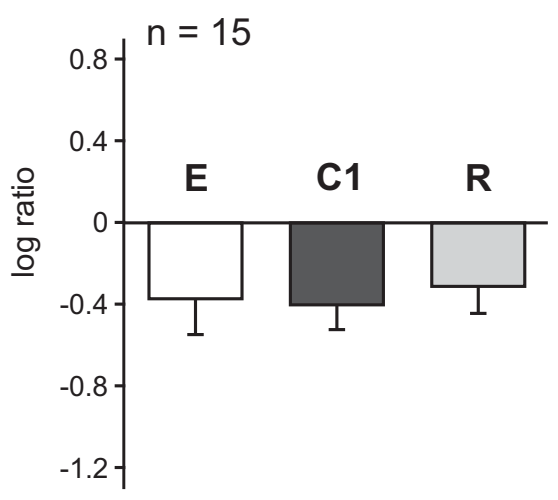

B Double-cough response

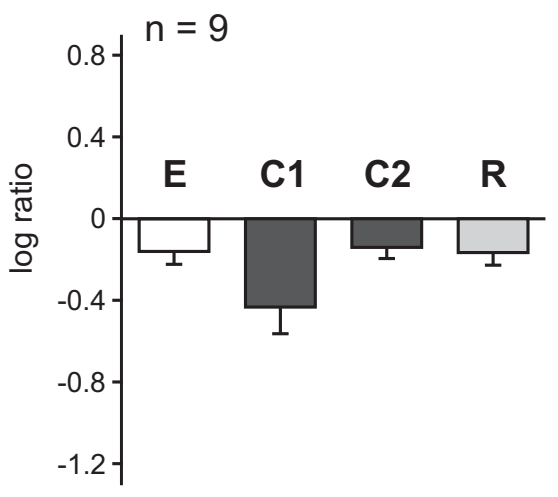

c Triple-cough response

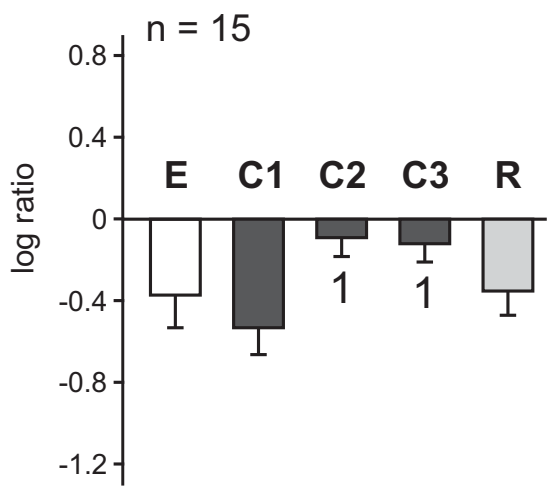

FIGURE 3 | Average log ratios of I-Aug neurons during (A) single-, (B) double-, and (C) triple-cough episodes. 1, Significantly different from C1 $(p<0.02)$. Number of neurons $(n)$ analyzed for each cough episode type is indicated on the plots. Some neurons were evaluated for more than one type of cough response. Error bars indicate the standard error of the mean.

then gradually declined during subsequent cycles (Figure 5). Phrenic amplitude was significantly greater during C1 $(p<0.001$, $p<0.001$, and $p<0.001$, respectively) as well as during $\mathrm{C} 2$

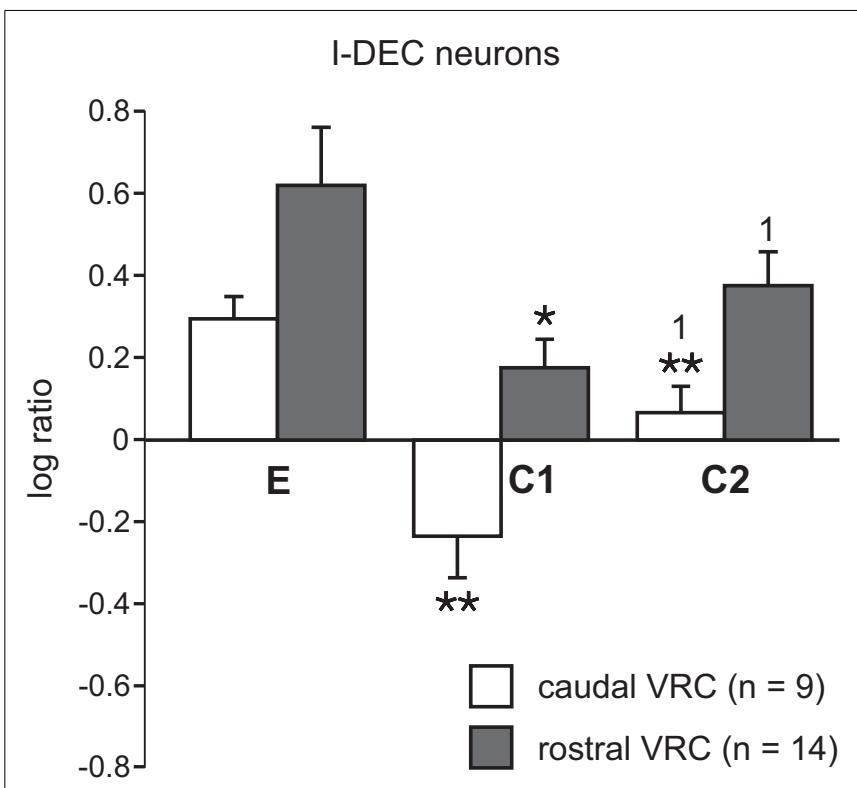

FIGURE 4 | Average log ratios of I-Dec neurons in the cVRC and rVRC.

The first (C1) and second (C2) cough cycles from all repetitive cough episodes were analyzed. ${ }^{*}$, Significantly different from $E ; 1$, significantly different from C1. $P$-values are indicated by one $(p<0.02)$ or two $(p<0.001)$ symbols. Error bars indicate the standard error of the mean.

$(p<0.001$ and $p=0.002)$ of single-, double-, and triple-cough response episodes when compared to maximum amplitudes during eupnea. Furthermore, maximum phrenic amplitude during C1 was significantly greater than the amplitude during C2 for double-cough episodes $(p<0.001)$, and greater than amplitudes during C2 and C3 for triple-cough responses $(p=0.008$ and $p=0.012$, respectively). There was no difference in integrated phrenic amplitudes during C2 and C3 in triple-cough episodes.

\section{Inspiratory Duration}

As illustrated in Figure 6, cough inspiratory time $\left(\mathrm{CT}_{\mathrm{I}}\right)$ was significantly longer during $\mathrm{Cl}$ cycles in averaged single-, double-, and triple-cough responses when compared with eupneic $(p<0.001$, $p<0.001$, and $p=0.001$, respectively) and recovery breaths $(p<0.001,0.001,0.001) . \mathrm{CT}_{\mathrm{I}}$ during $\mathrm{C} 1$ and $\mathrm{C} 2$ were significantly different for double- and triple-cough responses $(p<0.001$ and 0.001 ), but there was no difference in $\mathrm{CT}_{\mathrm{I}}$ between $\mathrm{C} 2$ and $\mathrm{C} 3$ in triple-cough episodes. There were also no differences in $\mathrm{CT}_{\mathrm{I}}$ during $\mathrm{C} 1$ for single-, double-, and triple-cough episodes or during C2 for double- and triple-cough responses.

\section{EVIDENCE FOR INSPIRATORY PHASE MODULATION OF TONIC EXPIRATORY NEURON INHIBITION OF INSPIRATORY DRIVE DURING MULTIPLE COUGHS}

The firing rate histograms of six cells (four VRC augmenting inspiratory neurons and two tonic expiratory neurons) recorded during a double-cough response to tracheal stimulation are shown in Figure 7A; these cells were recorded simultaneously with 10 other neurons and integrated phrenic and lumbar nerve activities. Neurons 51,57 , and 62 were recorded from animal J and are included 
Table 2 | Average discharge identities of I-Dec and I-Aug VRC neurons during the control period and the first two cough cycles in a multiple-cough response to intra-tracheal stimulation.

\begin{tabular}{|c|c|c|c|c|c|c|c|}
\hline \multicolumn{2}{|c|}{ Discharge identity } & \multicolumn{2}{|c|}{ Total VRC } & \multicolumn{2}{|c|}{ cVRC } & \multicolumn{2}{|c|}{ rVRC } \\
\hline Control & During cough & C1 & $\mathrm{C2}$ & C1 & $\mathrm{C2}$ & C1 & $\mathrm{C2}$ \\
\hline \multirow[t]{2}{*}{ I-Dec $(n=23)$} & Changed to I-Aug & 10 & 6 & 7 & 4 & 3 & 2 \\
\hline & Unchanged & 13 & 17 & 2 & 5 & 11 & 12 \\
\hline \multirow[t]{2}{*}{ I-Aug $(n=17)$} & Changed to I-Dec & 1 & 2 & 0 & 1 & 1 & 1 \\
\hline & Unchanged & 16 & 15 & 14 & 13 & 2 & 2 \\
\hline
\end{tabular}

in Table 1; I cell 66 could not be evaluated for a change in discharge identity during a cough response because it was recruited by the tracheal stimulus and so is not included in the table. The activity of each I cell increased during the cough cycles, whereas the activity of the E-Tonic neurons decreased. Cross-correlograms from pairs of represented neurons are shown in Figure 7B. The central peak (Figure 7B1) in the correlogram for the tonic E neurons (cells 49 and 55) is consistent with a shared coordinating influence. Correlograms triggered by both tonic expiratory neurons for each respective target inspiratory neuron (cells 62 and 57) had an offset trough feature indicative of putative inhibitory actions (Figures 7B2,3). The offset peak in the correlogram for the inspiratory neuron pair (Figure 7B4) is consistent with an excitatory action of cell 62 upon neuron 57. The correlation linkage map (Figure 7D) summarizes all pair-wise correlation features involving the four cells of Figure 7B. Each large "sphere" corresponds to a neuron and is color-coded to reflect respiratory modulation; arrows indicate the direction of the firing rate change during the inspiratory phase of each cough response.

Spike-triggered averages of the full-wave-rectified contralateral phrenic nerve signal were consistent with relationships represented in the linkage map. The average triggered by inspiratory neuron 57 had an offset peak (arrow, Figure 7Ca). The offset trough (arrow, Figure $\mathbf{7 C b}$ ) in the average triggered by tonic expiratory neuron 55 provides further evidence for functional inhibition of antecedent elements of the excitatory inspiratory neuron chain contributing to inspiratory drive.

\section{DISCUSSION}

We report that a group of I-Dec neurons in the $\mathrm{CVRC}$, and to a lesser extent the rVRC, change their discharge identity from decrementing to augmenting during repetitive fictive cough. By the second cough cycle (C2), half of these I-Dec neurons returned to their eupneic decrementing firing pattern. I-Aug neurons, on the other hand, maintained their augmenting discharge identity during repetitive cough. Inspiratory phase duration was longer and phrenic burst amplitude was greater within the first cough cycle (C1) compared to eupnea. However, phase duration shortened and phrenic amplitude decreased in subsequent coughs. These results highlight a unique property of a subset of inspiratory neurons that reconfigure their discharge identity during repetitive cough.

Cough was elicited in these studies in paralyzed animals. Also known as fictive cough, the motor patterns of this behavior bear significant similarities and differences to the same behavior produced in unparalyzed animals. Abdominal motor patterns during fictive and unparalyzed cough are very similar in rise times and relative increases in magnitudes (Bolser, 1991; Bolser and Davenport, 2000; Wang et al., 2009). Inspiratory motor patterns during cough do differ somewhat, with the magnitude of inspiratory motor drive during fictive cough being less than that produced in animals that are unparalyzed (Bolser, 1991; Bolser and DeGennaro, 1994; Bolser and Davenport, 2000). The specific mechanism(s) that underlie this difference in motor drive are unknown. However, as shown in this report, the duration of the inspiratory phase of the first cough of a series is prolonged in the fictive model, just as it is in unparalyzed animals (Tatar et al., 1994; Bolser and Davenport, 2000). Our findings are very relevant to the mechanism of this inspiratory prolongation and likely apply to both paralyzed and unparalyzed animals. Furthermore, a series of investigators (Jakuš et al., 1985, 1987; Bongianni et al., 1998) have recorded the behavior of medullary respiratory neurons during cough in unparalyzed animals and their findings are very similar to observations made during fictive cough on the same populations of cells (Shannon et al., 1996, 1998, 2000).

\section{LOG DISCHARGE RATIO}

We applied a straight-forward metric of discharge pattern to the population of inspiratory neurons that we recorded. The log ratio of spike counts in the first and second halves of the inspiratory phase provided both quantitative and qualitative information regarding the discharge patterns of the neurons on a cycle-by-cycle basis. Other analyses of discharge pattern and breathing modulation (e.g., eta-squared, cycle-triggered histograms, see Cohen, 1968; Orem and Dick, 1983) are based on averaging or accumulating spike data over many breathing cycles. These metrics are most useful when applied to relatively stationary motor patterns or between prolonged changes in state/excitability of the respiratory motor system. Airway protective behaviors, such as cough, represent transient changes in motor drive to respiratory muscles that often span less than five cycles. Furthermore, phase durations can be widely variant on a cycle-by-cycle basis during cough; this can lead to "smearing" of cycle-triggered histograms, which can limit their utility when applied to this behavior.

\section{DISCHARGE IDENTITY DURING SINGLE COUGHS}

Many of the same neural elements that generate breathing also contribute to the production of cough. Shannon and coworkers (Shannon et al., 1998, 2000; Baekey et al., 2001) proposed that this network is reconfigured to produce protective airway defense 

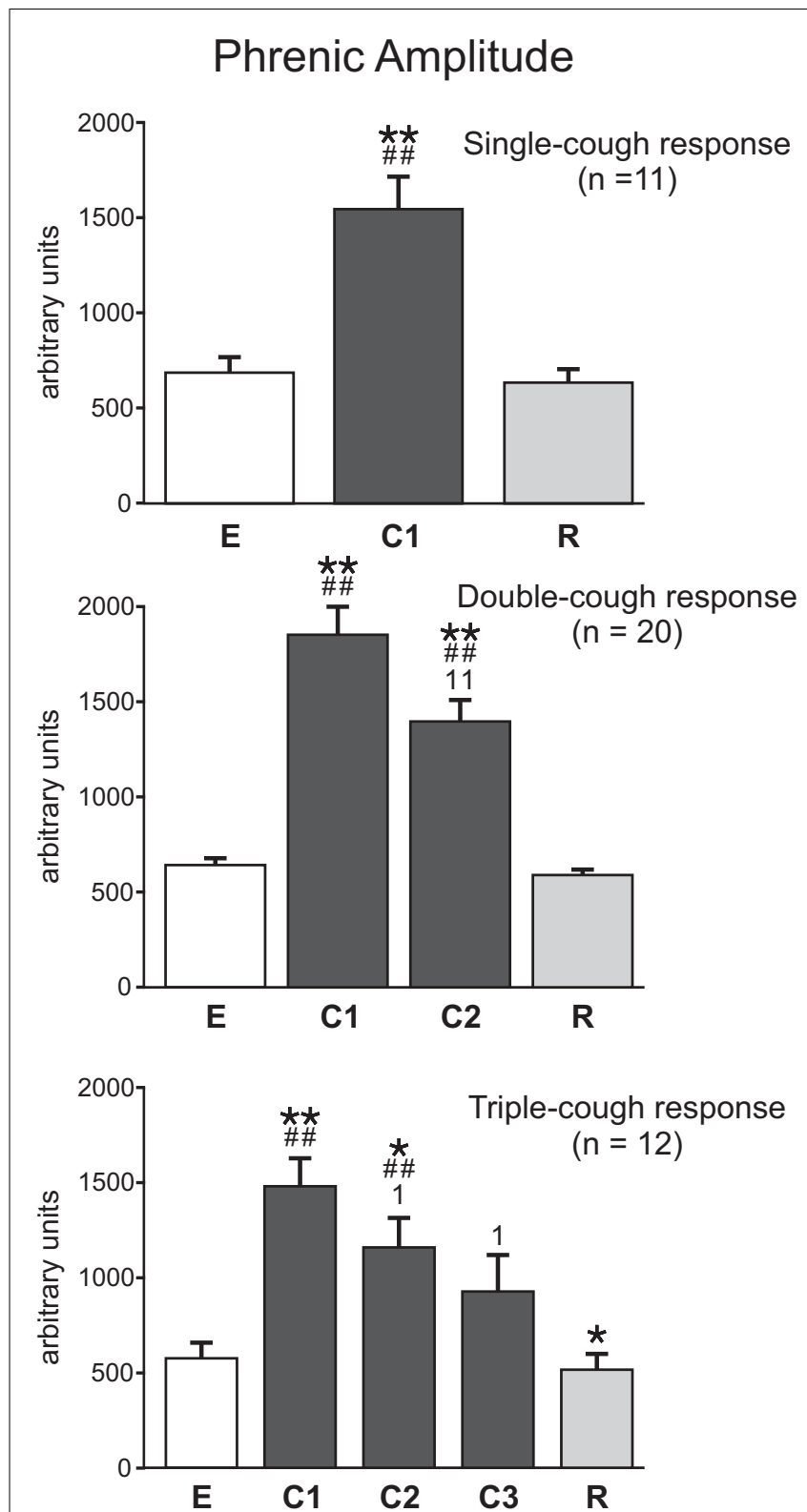

FIGURE 5 | Average phrenic burst amplitude (in arbitrary units, au) during single-, double-, and triple-cough episodes (top, middle, and bottom panels, respectively). Values for a given cough cycle (e.g., C1) were not different among these three cough response types. ${ }^{*}$ Significantly different from $\mathrm{E}$; \#, significantly different from $\mathrm{R}$; 1 , significantly different from C1. $P$-values are indicated by one $(p<0.02)$ or two $(p<0.001)$ symbols. Error bars indicate the standard error of the mean.

reflexes (such as cough, expiration reflex, sigh, gasp, sneeze, aspiration, and swallow) that have motor patterns distinctly different from breathing (Jakuš et al., 1985; Oku et al., 1994; Gestreau et al., 1996, 2000; Lieske et al., 2000; Saito et al., 2003; Baekey et al., 2004). Reconfiguration is a process by which a network of neurons is reorganized through changes in their neuronal discharge patterns and functional interactions to modify motor output (Getting and

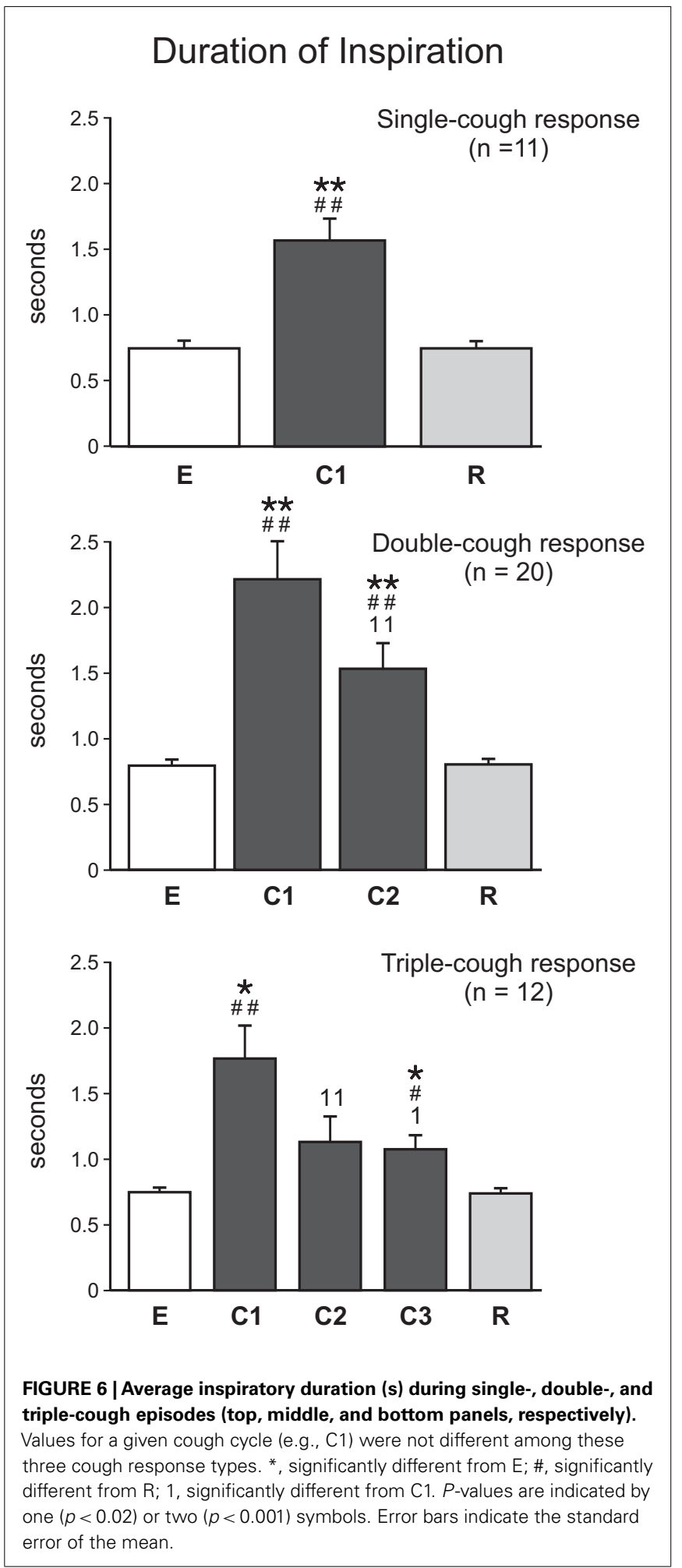

Dekin, 1985). Changes in neural discharge are typically quantified in terms of burst frequency and duration. During cough, the majority of inspiratory and expiratory neurons increase their discharge firing rate, while a smaller proportion maintain their firing rate or even decrease it (Jakuš et al., 1985, 1987; Oku et al., 1994; 
Bongianni et al., 1998; Shannon et al., 1998, 2000; Gestreau et al., 2000; Baekey et al., 2001). Previous in vivo studies have shown that some populations of inspiratory and expiratory neurons change their discharge identity during cough (Orem and Trotter, 1993; Oku et al., 1994; Shannon et al., 1998, 2000), although published models describing reconfiguration of the respiratory neural network during cough have primarily highlighted expiratory neuron subpopulations as having labile discharge identities (Shannon et al., 1998, 2000; Bolser et al., 2006).

Reconfiguration of the central pattern generator during the inspiratory phase of cough included a switch in the discharge identity of approximately one-half of the I-Dec neurons: $43 \%$ of I-Dec neurons changed their discharge identity during $\mathrm{C} 1$. This result extends the observation of Shannon et al. (1998) who reported that $55 \%$ of I-Dec neurons recorded had a predominately augmenting discharge during single coughs or $\mathrm{C} 1$ of a multi-cough response episode. The paucity of I-Aug neurons (6\%) that changed their discharge identity during $\mathrm{C} 1$ is in agreement with previous studies (Shannon et al., 1998, 2000).

Changes in discharge identity during cough have been reported for expiratory respiratory neurons (Oku et al., 1994; Shannon et al., 1998, 2000). Many E-Aug neurons in the rVRC and cVRC shift to a decrementing discharge pattern during single coughs or the first in a series of coughs (Shannon et al., 1998). The switch of cVRC E-Aug premotor neurons to a discharge pattern that matches the motor activity pattern in expiratory muscles may be a means to generate the muscle force and abdominal pressure required to propel air through the airways during the expulsive phase of cough (Bongianni et al., 1998; Shannon et al., 1998, 2000). Similarly, shifting I-Dec premotor and motoneurons to an augmenting pattern that mirrors the motor activity of inspiratory pump muscles (Grelot and Milano, 1991; Iscoe and Grelot, 1992; Milano et al., 1992) would allow for large increases in lung volume necessary to generate the expiratory airflow rates that will move material from the airway by increasing inspiratory muscle activation and enlarging the larynx.

Inspiratory neurons have been observed to switch their discharge identity during other airway protective behaviors. For instance, I-Dec neurons can shift to an augmenting discharge pattern during augmented breaths (Orem and Trotter, 1993). Thus, a change in discharge identity is not unique to cough and may be an important property of the mechanism by which the central pattern generator reconfigures to produce different airway protective behaviors.

The firing rate modulation of tonic expiratory neurons during cough and their functional interactions with VRC inspiratory neurons and phrenic motor neurons suggest that disinhibition contributes to the inspiratory drive of cough. These results are consistent with predictions based on recent computational models for cough motor pattern generation that include multiple circuit paths for cough receptor-mediated inspiratory drive modulation (Rybak et al., 2008; Poliacek et al., 2011; O'Connor et al., 2012). The transient switch of propriobulbar I-Dec neurons to an augmenting pattern during cough may be a component of mechanisms for enhanced suppression of tonic E neuron activity during coughs. In this context, we also note that evidence for inspiratory phase suppression of tonic E neurons by I-Dec neurons has been reported in a study on central chemoreceptor-mediated enhancement of inspiratory drive (Ott et al., 2012). A similar suppression of tonic expiratory neuron activity and the attendant inspiratory drive enhancement during cough could operate to balance the inspiratory-suppressive influence of increased blood pressure and excitation of tonic expiratory neurons caused by cough mechanics (Poliacek et al., 2011).

\section{DISCHARGE IDENTITY DURING REPETITIVE COUGHS}

To our knowledge, this is the first study to describe the discharge identity of inspiratory neurons during repetitive coughing behaviors. Approximately half of the I-Dec neurons included in this study changed to an augmenting discharge patterns during $\mathrm{C} 1$ and/or C2, whereas only a small portion of I-Aug neurons changed their discharge identity during $\mathrm{C} 1$ or $\mathrm{C} 2$. The neural mechanisms and synaptic or afferent effects that occur during the second half of a cough inspiratory phase to produce an augmenting pattern in some I-Dec neurons are unknown, but several possibilities can be considered.

1. Input from recruited neurons. Inspiratory neurons that are recruited or evoked by the cough stimulus (such as neuron 66 in Figure 7) may have an excitatory effect on some I-Dec neurons, transiently converting their discharge identities.

2. Enhanced input from I-Aug neurons. A second possible mechanism was incorporated into a model developed by O'Connor et al. (2012) to produce prolonged inhibition of tonic E neurons by I-Dec cells. This approach involves a separate population of inhibitory I-Dec neurons whose excitation by I-Aug cells is presynaptically inhibited by tonic decrementing expiratory neurons (tonic E-Dec cells). In this mechanism, enhanced activity of I-Aug and I-Dec cells during cough produces an increased inhibition of the tonic E-Dec neurons; the ensuing lessening of the presynaptic inhibition provided by the tonic E-Dec cells leads to a greater excitatory influence of the I-Aug neurons upon the I-Dec cells, possibly imparting on them an augmenting discharge pattern.

3. Influences of cells in other brainstem areas. The activities of raphé and pontine neurons are also affected by cough (e.g., see Jakuš et al., 1998; Baekey et al., 2003; Poliacek et al., 2004; Shannon et al., 2004) and could provide a network modulatory influence that briefly causes the discharge identity of an I-Dec neuron to assume an augmenting pattern.

4. Input from vagal afferents - slowly adapting pulmonary stretch receptors (SARs). Vagotomy in decerebrate cats changes the discharge identity of most pontine and raphé respiratory neurons (Dick et al., 2008; Morris et al., 2010), suggesting that alterations in vagal afferent activity can modify the discharge properties of respiratory neurons. During eupneic breathing in animals, lung inflation can terminate the inspiratory phase and enhance E-Dec activity (Hayashi et al., 1996). Coughing induces large changes in tidal volume, which would be expected to stimulate SARs. Given that I-Dec neurons are suppressed by inflation during eupnea, SARs are unlikely to mediate the alteration in discharge identity of I-Dec neurons during coughing. 


\section{A}

Firing rate histograms

Resp. Cell

type ID

I-Aug 66

n

(1)

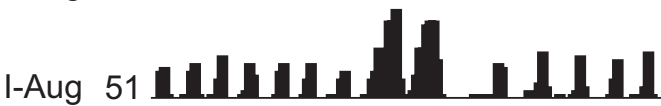

I-Aug 57

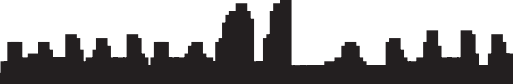

I-Aug 62

E-Tonic 55

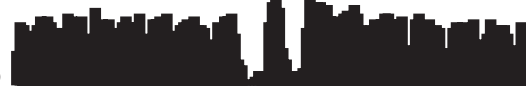

E-Tonic 49
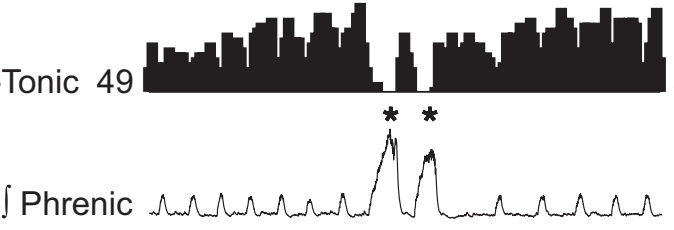

* *

$\int$ Lumbar

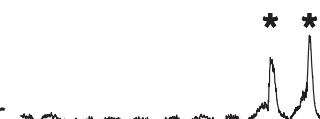

$75.0 \mathrm{~s}$

C

(a)

a) $57>$ Phrenic

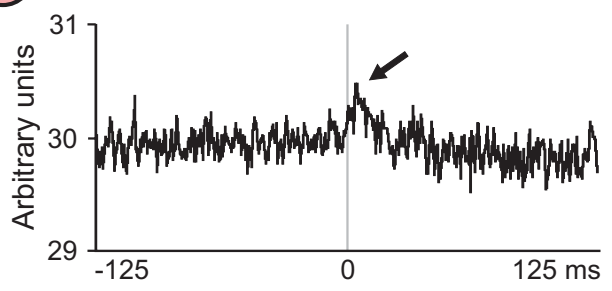

(b) $55>$ Phrenic

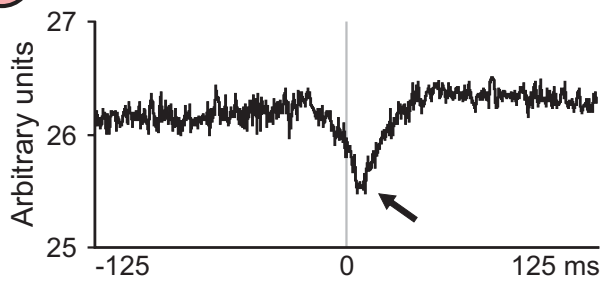

FIGURE 7 | Correlations among pairs of VRC I and E neurons responsive to cough-eliciting tracheal stimulation. (A) Firing rate histograms (binwidths $=375.0 \mathrm{~ms}$ ) for 6 of 16 simultaneously recorded neuron spike trains during a double-cough response to tracheal stimulation. For each trace, the respiratory-modulated pattern, cell identification number, and maximum firing rate are shown. ${ }^{*}$, Amplitude of integrated phrenic (lumbar) nerve activity is $\geq 2$ SD above the mean maximum amplitude during eupneic period.
46.0

46.0

62.0

B

Cross-correlograms

Max

pikes/sec 22.0

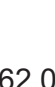

36.0

(3)

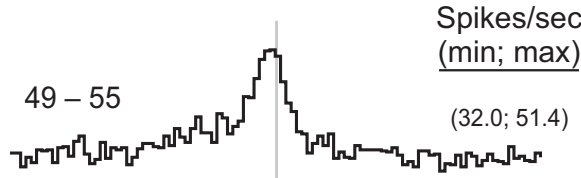

(2)
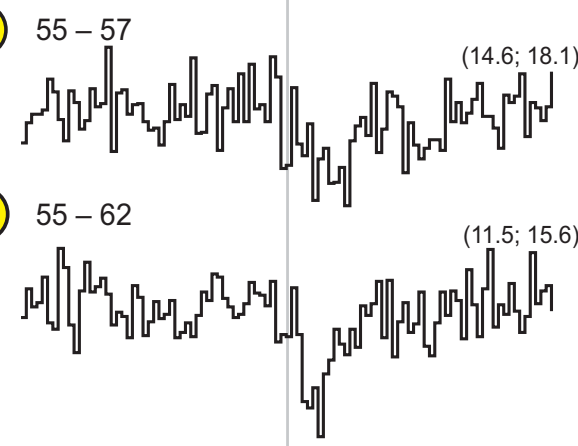

(4)

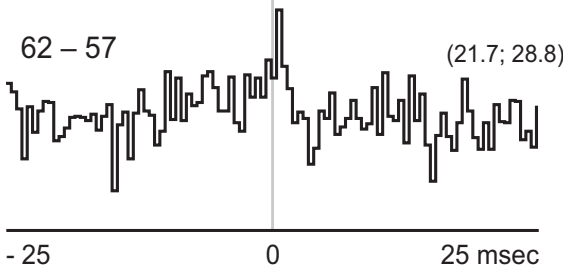

D Correlation linkage map

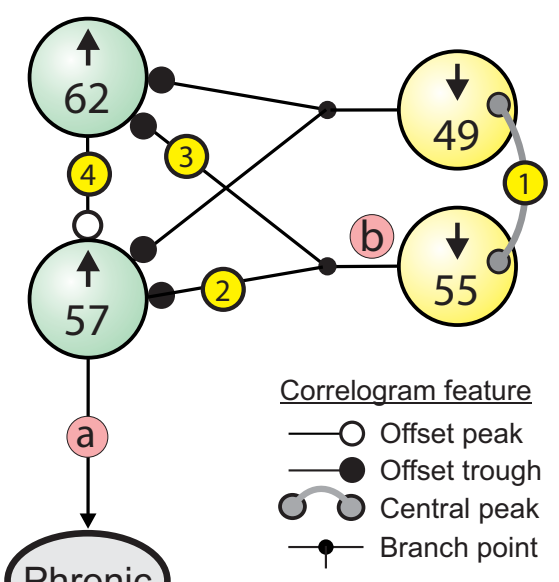

Respiratory modulation

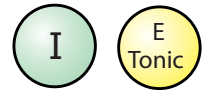

(B) Features in the $\mathrm{CCH}$ are included in the correlation linkage map shown in (D). Bin width for all $\mathrm{CCHs}=0.5 \mathrm{~ms}$. The minimum and maximum bin values, normalized to spikes per second per trigger event, are shown for each correlogram. Feature description, detectability index (equal to the ratio of the maximum amplitude of feature departure from background activity divided by the SD of the correlogram noise), half-width, and numbers of trigger neuron (Continued) 


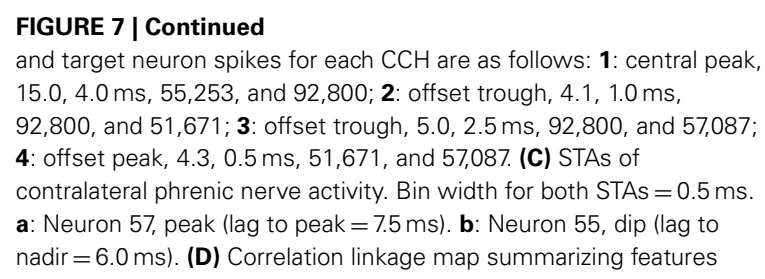

found in all CCHs calculated for the group of four neurons in (B). Each large "sphere" represents a neuron and contains that neuron's ID code and direction of change in firing rate when tracheal stimulation elicited a cough; the cell's respiratory-modulated firing pattern is indicated by the color of the sphere (see Key). White, black, and gray circles at the ends of the lines between spheres represent central or offset peaks or troughs (see Key). Circled numbers indicate corresponding $\mathrm{CCH}$ shown in (B).
Peripheral chemosensory afferents are not likely to influence the activity patterns of inspiratory neurons nor modulate phase durations during a bout of cough: Hypocapnia [a consequence of repetitive coughing (unpublished observation)] blunts carotid chemoreceptor activity (Dejours, 1963) but does not inhibit cough (Suzuki et al., 1991).

Half of the 10 I-Dec cells that changed their discharge identity during the first cough of a response returned to their pre-cough I-Dec pattern during C2. This trend continued for C3 and subsequent cough cycles. The neural processes that account for the return of eupneic discharge identity before the cough episode has ended are unknown. Canning et al. $(2004,2006)$ have proposed the existence of specific cough receptors that are activated by stimulants similar to those that generate cough, including mechanical stimulation of the intrathoracic trachea used in the present study. We and others (Bongianni et al., 1998; Bolser and Davenport, 2000) have reported that repetitive cough behaviors occurred after mechanical stimulation of the airway was terminated. A reduction in afferent input from specific cough receptors following tracheal stimulation may account for the return of some I-Dec neurons to their eupneic discharge identity by the second cough cycle.

Another mechanism that could explain the transitory nature of changes in discharge identity during repetitive cough involves SARs and their permissive effect on cough. Blocking SAR activity with $\mathrm{SO}_{2}$ in rabbits decreases the strength and frequency of cough induced by mechanical stimulation of the trachea (Hanácek et al., 1981). It has been proposed that the excitability of a cough gate mechanism modulated by SAR afferent feedback accounts for the permissive effect of SARs on the cough reflex (Hanácek et al., 1981; Sant'Ambrogio et al., 1984; Romaniuk et al., 1997; Bolser et al., 2006). It is unknown whether the effects of SARs on cough generation are the same on a cycle-by-cycle basis during repetitive cough. A decrease in the excitability of a threshold gating mechanism due to changes in SAR input during an episode of repetitive coughing could reduce the probability that a cough will be generated. This may be responsible for the return of some I-Dec neurons to their eupneic discharge identity.

\section{REGIONAL DIFFERENCES IN NEURON DISCHARGE IDENTITY DURING REPETITIVE COUGHS}

In the present study, a larger proportion of I-Dec neurons in the cVRC changed their discharge identity during repetitive cough compared to the rVRC. This is consistent with the results from Shannon et al. (1998) during single coughs. Regional differences in I-Dec discharge identities during cough may be an important component of the reconfiguration process. Shannon et al. (1998, 2000) proposed that early E-Aug neurons in the rVRC that switch to a decrementing discharge identity during cough provide excitatory input to cVRC bulbospinal E-Aug neurons (i.e., premotor expiratory neurons). The decrementing pattern of activity of the early and premotor E-Aug neurons matches the discharge pattern of expiratory motoneurons (Shannon et al., 1998, 2000). Furthermore, the activity duration of these neurons is limited by inhibitory input from rVRC late E-Aug neurons that do not change their discharge identity during cough. Thus, the discharge identity of E-Aug neurons and their location within the VRC may help characterize their role in the reconfiguration process during the expiratory phase of cough. An analogous relationship might exist for I-Dec neurons during the inspiratory phase of cough reported in the present study. For instance, I-Dec neurons in the cVRC may help augment phrenic discharge during cough by switching to an augmenting pattern that matches inspiratory pump muscle activity. In support of this view, we report that three of the cVRC I-Dec neurons that changed their discharge identity were bulbospinal and one was premotor to the phrenic motoneuron pool. I-Dec neurons in the rVRC that retain their discharge identity may help lengthen the inspiratory phase duration by inhibiting expiratory neurons (Shannon et al., 1998, 2000; Bolser et al., 2003). Axonal projections from I-Dec neurons with somas in the retrofacial nucleus near the rVRC to the nucleus ambiguus and reticular formation have been shown histologically with HRP labeling (Otake et al., 1990), suggesting extensive anatomical connections between the rVRC I-Dec neurons and the respiratory network.

Peripheral sensory afferent input has been shown to induce regional differences in the inspiratory neural reconfiguration process. For instance, activation of carotid chemoreceptors decreases I-Driver neural activity in the rVRC which in turn decreases inspiratory duration, but increases premotor I-Aug activity in the cVRC which augments phrenic burst amplitude (Morris et al., 1996). Other peripheral afferents such as the "cough receptors" may also demonstrate similar region-specific effects on the respiratory neural network.

\section{CONCLUSIONS AND PERSPECTIVES}

The results from this study highlight an important property of the reconfiguration process that has not been previously described for medullary inspiratory neurons during repetitive coughs as it has been for single coughs (Shannon et al., 1996, 1998). I-Dec neurons in the cVRC change their discharge identity during cough. Furthermore, as some I-Dec neurons returned to a decrementing discharge identity by the second and subsequent cough cycles, phrenic activity, and inspiratory duration also returned to its pre-cough stimulus eupneic patterns, suggesting that changes in discharge identity of I-Dec neurons within the respiratory neural network may play an important role in modifying inspiratory motor pattern during repetitive cough. Given the connectivity of I-Dec neurons and their integral role in shaping neural activity 
within the respiratory network, a cough model that incorporates changing discharge identities of inspiratory neurons during sustained airway protective behaviors, such as repetitive cough, may be important to accurately predict the resulting respiratory motor patterns. A possible modification of the cough neural network proposed by Shannon et al. $(1998,2000)$ may include a subset of I-Dec neurons in the cVRC that send excitatory inputs to phrenic motoneurons in the form of an augmenting activity pattern either

\section{REFERENCES}

Baekey, D. M., Morris, K. F., Gestreau, C., Li, Z., Lindsey, B. G., and Shannon, R. (2001). Medullary respiratory neurones and control of laryngeal motoneurones during fictive eupnoea and cough in the cat. $J$. Physiol. (Lond.) 534, 565-581.

Baekey, D. M., Morris, K. F., Nuding, S. C., Segers, L. S., Lindsey, B. G., and Shannon, R. (2003). Medullary raphé neuron activity is altered during fictive cough in the decerebrate cat. J. Appl. Physiol. 94, 93-100.

Baekey, D. M., Morris, K. F., Nuding, S. C., Segers, L. S., Lindsey, B. G., and Shannon, R. (2004). Ventrolateral medullary respiratory network participation in the expiration reflex in the cat. J. Appl. Physiol. 96, 2057-2072.

Benjamini, Y., and Hochberg, Y. (1995). Controlling the false discovery rate: a practical and powerful approach to multiple testing. J. R. Stat. Soc. Series B Stat. Methodol. 57, 289-300.

Bolser, D. C. (1991). Fictive cough in the cat. J. Appl. Physiol. 71, 2325-2331.

Bolser, D. C., and Davenport, P. W. (2000). Volume-timing relationships during cough and resistive loading in the cat. J. Appl. Physiol. 89, 785-790.

Bolser, D. C., Davenport, P. W., Golder, F. J., Baekey, D. M., Morris, K. F., Lindsey, B. G., and Shannon, R. (2003). "Neurogenesis of cough," in Cough: Causes, Mechanisms and Therapy, eds H. Boushey, K. F. Chung, and J. Widdicombe (Oxford: Blackwell Publishing), 173-180.

Bolser, D. C., and DeGennaro, F. C. (1994). Effect of codeine on the inspiratory and expiratory burst pattern during fictive cough in cats. Brain Res. 662, 25-30.

Bolser, D. C., Poliacek, I., Jakuš, J., Fuller, D. D., and Davenport, P. W. (2006). Neurogenesis of cough, other airway defensive behaviors and breathing: a holarchical system? Respir. Physiol. Neurobiol. 152, 255-265.

Bongianni, F., Mutolo, D., Fontana, G. A., and Pantaleo, T. (1998). Discharge patterns of Bötzinger complex neurons during cough in the cat. Am. J. Physiol. 274, R1015R1024.
Canning, B. J., Mazzone, S. B., Meeker, S. N., Mori, N., Reynolds, S. M., and Undem, B. J. (2004). Identification of the tracheal and laryngeal afferent neurones mediating cough in anaesthetized guinea-pigs. J. Physiol. (Lond.) 557, 543-558.

Canning, B. J., Mori, N., and Mazzone, S. B. (2006). Vagal afferent nerves regulating the cough reflex. Respir. Physiol. Neurobiol. 152, 223-242.

Cohen, M. I. (1968). Discharge patterns of brain-stem respiratory neurons in relation to carbon dioxide tension. J. Neurophysiol. 31, 142-165.

Dejours, P. (1963). Control of respiration by arterial chemoreceptors. Ann. N. Y. Acad. Sci. 109, 682-695.

Dick, T. E., Shannon, R., Lindsey, B. G., Nuding, S. C., Segers, L. S., Baekey, D. M., and Morris, K. F. (2008). Pontine respiratory-modulated activity before and after vagotomy in decerebrate cats. J. Physiol. (Lond.) 586, 4265-4282.

Gestreau, C., Grelot, L., and Bianchi, A. L. (2000). Activity of respiratory laryngeal motoneurons during fictive coughing and swallowing. Exp. Brain Res. 130, 27-34.

Gestreau, C., Milano, S., Bianchi, A. L., and Grelot, L. (1996). Activity of dorsal respiratory group inspiratory neurons during laryngeal-induced fictive coughing and swallowing in decerebrate cats. Exp. Brain Res. 108, 247-256.

Getting, P. A., and Dekin, M. S. (1985). Mechanisms of pattern generation underlying swimming in Tritonia. IV. Gating of central pattern generator. J. Neurophysiol. 53, 466-480.

Grelot, L., and Milano, S. (1991). Diaphragmatic and abdominal muscle activity during coughing in the decerebrate cat. Neuroreport 2, 165-168.

Hanácek, J., Widdicombe, J. G., and Korpás, J. (1981). Effect of SO2 inhalation on the cough reflex in rabbits. Cesk. Fysiol. 30, 243-245.

Hayashi, F., Coles, S. K., and McCrimmon, D. R. (1996). Respiratory neurons mediating the Breuer-Hering reflex prolongation of expiration in rat. J. Neurosci. 16, 6526-6536.

Iscoe, S., and Grelot, L. (1992). Regional intercostal activity during coughing

through monosynaptic or polysynaptic connections via excitatory premotor I-Aug neurons.

\section{ACKNOWLEDGMENTS}

We thank Peter Barnhill, Jan Gilliland, Rebecca McGowan, and Zhongzeng Li for excellent technical assistance. This research was supported by NIH R33 HL89104, R33 HL89071, and R01 HL103415.

and vomiting in decerebrate cats. Can. J. Physiol. Pharmacol. 70, 1195-1199.

Jakuš, J., Stránsky, A., Poliacek, I., Baráni, H., and Boselova, L. (1998). Effects of medullary midline lesions on cough and other airway reflexes in anaesthetized cats. Physiol. Res. 47, 203-213.

Jakuš, J., Tomori, Z., and Stransky, A. (1985). Activity of bulbar respiratory neurones during cough and other respiratory tract reflexes in cats. Physiol. Bohemoslov. 34, 127-136.

Jakuš, J., Tomori, Z., Stransky, A., and Boselova, L. (1987). Bulbar respiratory activity during defensive airways reflexes in cats. Acta Physiol. Hung. 70, 245-254.

Lieske, S. P., Thoby-Brisson, M., Telgkamp, P., and Ramirez, J. M. (2000). Reconfiguration of the neural network controlling multiple breathing patterns: Eupnea, sighs and gasps [see comment]. Nat. Neurosci. 3, 600-607.

Milano, S., Grelot, L., Bianchi, A. L., and Iscoe, S. (1992). Discharge patterns of phrenic motoneurons during fictive coughing and vomiting in decerebrate cats. J. Appl. Physiol. 73, 1626-1636.

Morice, A. H., Fontana, G. A., Sovijarvi, A. R., Pistolesi, M., Chung, K. F., Widdicombe, J., O'Connell, F., Geppetti, P., Gronke, L., De Jongste, J., Belvisi, M., Dicpinigaitis, P., Fischer, A., McGarvey, L., Fokkens, W. J., and Kastelik, J. (2004). The diagnosis and management of chronic cough. Eur. Respir. J. 24, 481-492.

Morris, K. F., Arata, A., Shannon, R., and Lindsey, B. G. (1996). Inspiratory drive and phase duration during carotid chemoreceptor stimulation in the cat: medullary neurone correlations. J. Physiol. (Lond.) 491, 241-259.

Morris, K. F., Nuding, S. C., Segers, L. S., Baekey, D. M., Shannon, R., Lindsey, B. G., and Dick, T. E. (2010). Respiratory and Mayer wave-related discharge patterns of raphé and pontine neurons change with vagotomy. J. Appl. Physiol. 109, 189-202.

O'Connor, R., Segers, L. S., Morris, K. F., Nuding, S. C., Pitts, T., Bolser,
D. C., Davenport, P. W., and Lindsey, B. G. (2012). A joint computational respiratory neural networkbiomechanical model for breathing and airway defensive behaviors. Front. Physio. 3:264. doi: 10.3389/fphys.2012.00264

Oku, Y., Tanaka, I., and Ezure, K. (1994). Activity of bulbar respiratory neurons during fictive coughing and swallowing in the decerebrate cat. $J$. Physiol. (Lond.) 480, 309-324.

Orem, J., and Dick, T. (1983). Consistency and signal strength of respiratory neuronal activity. J. Neurophysiol. 50, 1098-1107.

Orem, J., and Trotter, R. H. (1993). Medullary respiratory neuronal activity during augmented breaths in intact unanesthetized cats. J. Appl. Physiol. 74, 761-769.

Otake, K., Sasaki, H., Ezure, K., and Manabe, M. (1990). Medullary projection of nonaugmenting inspiratory neurons of the ventrolateral medulla in the cat. J. Comp. Neurol. 302, 485-499.

Ott, M. M., Nuding, S. C., Segers, L. S., O'Connor, R., Morris, K. F., and Lindsey, B. G. (2012). Central chemoreceptor modulation of breathing via multipath tuning in medullary ventrolateral respiratory column circuits. J. Neurophysiol. 107, 603-617.

Poliacek, I., Jakuš, J., Stránsky, A., Baráni, H., Halašová, E., and Tomori, Z. (2004). Cough, expiration and aspiration reflexes following kainic acid lesions to the pontine respiratory group in anaesthetized cats. Physiol. Res. 53, 155-170.

Poliacek, I., Morris, K. F., Lindsey, B. G., Segers, L. S., Rose, M. J., Corrie, L. W.-C., Wang, C., Pitts, T. E., Davenport, P. W., and Bolser, D. C. (2011). Blood pressure changes alter tracheobronchial cough: computational model of the respiratory-cough network and in vivo experiments in anesthetized cats. J. Appl. Physiol. 111, 861-873.

Romaniuk, J. R., Kowalski, K. E., and Dick, T. E. (1997). The role of pulmonary stretch receptor activation during cough in dogs. Acta Neurobiol. Exp. (Wars) 57, 21-29. 
Rybak, I. A., O’Connor, R., Ross, A., Shevtsova, N. A., Nuding, S. C., Segers, L. S., Shannon, R., Dick, T. E., Dunin-Barkowski, W. L., Orem, J. M., Solomon, I. C., Morris, K. F., and Lindsey, B. G. (2008). Reconfiguration of the pontomedullary respiratory network: a computational modeling study with coordinated in vivo experiments. J. Neurophysiol. 100, 1770-1799.

Saito, Y., Ezure, K., Tanaka, I., and Osawa, M. (2003). Activity of neurons in ventrolateral respiratory groups during swallowing in decerebrate rats. Brain Dev. 25, 338-345.

Sant'Ambrogio, G., Sant'Ambrogio, F. B., and Davies, A. (1984). Airway receptors in cough. Bull. Eur. Physiopathol. Respir. 20, 43-47.

Shannon, R., Baekey, D. M., Morris, K. F., Li, Z., and Lindsey, B. G. (2000). Functional connectivity among ventrolateral medullary respiratory neurones and responses during fictive cough in the cat. $J$. Physiol. (Lond.) 525, 207-224.

Shannon, R., Baekey, D. M., Morris, K. F., and Lindsey, B. G. (1996). Brainstem respiratory networks and cough. Pulm. Pharmacol. 9, 343-347.

Shannon, R., Baekey, D. M., Morris, K. F., and Lindsey, B. G. (1998). Ventrolateral medullary respiratory network and a model of cough motor pattern generation. J. Appl. Physiol. 84, 2020-2035.

Shannon, R., Baekey, D. M., Morris, K. F., Nuding, S. C., Segers, L. S., and Lindsey, B. G. (2004). Production of reflex cough by brainstem respiratory networks. Pulm. Pharmacol. Ther. 17, 369-376.

Smith, J. A., Aliverti, A., Quaranta, M., McGuinness, K., Kelsall, A., Earis, J., and Calverley, P. M. (2012). Chest wall dynamics during voluntary and induced cough in healthy volunteers. J. Physiol. (Lond.) 590, 563-574.

Suzuki, H., Kondo, T., Yamabayashi, H., Kobayashi, I., and Ohta, Y. (1991). Influence of central respiratory activity on the cough response in anesthetized dogs. Jpn. J. Physiol. 41, 879-891.

Tatar, M., Sant'Ambrogio, G., and Sant'Ambrogio, F. B. (1994). Laryngeal and tracheobronchial cough in anesthetized dogs. J. Appl. Physiol. 76, 2672-2679.

Wang, C., Saha, S., Rose, M. J., Davenport, P. W., and Bolser, D. C. (2009). Spatiotemporal regulation of the cough motor pattern. Cough 5,12 .

Conflict of Interest Statement: The authors declare that the research was conducted in the absence of any commercial or financial relationships that could be construed as a potential conflict of interest.
Received: 15 March 2012; paper pending published: 23 April 2012; accepted: 03 June 2012; published online: 29 June 2012.

Citation: Segers LS, Nuding SC, Vovk A, Pitts T, Baekey DM, O'Connor $R$, Morris KF, Lindsey BG, Shannon $R$ and Bolser DC (2012) Discharge identity of medullary inspiratory neurons is altered during repetitive fictive cough. Front. Physio. 3:223. doi: 10.3389/fphys.2012.00223

This article was submitted to Frontiers in Computational Physiology and Medicine, a specialty of Frontiers in Physiology. Copyright ( $\odot 2012$ Segers, Nuding, Vovk, Pitts, Baekey, O'Connor, Morris, Lindsey, Shannon and Bolser. This is an open-access article distributed under the terms of the Creative Commons Attribution Non Commercial License, which permits non-commercial use, distribution, and reproduction in other forums, provided the original authors and source are credited. 